\title{
Response to: Letter to the Editor "Universal Health Coverage in Iran: where we stand and how we can move forward"
}

\author{
Haniye Sadat Sajadi ${ }^{1}$, Elham Ehsani-Chimeh ${ }^{1}$, Reza Majdzadeh ${ }^{* 2}$ \\ Received: 27 Jul 2019 \\ Published: 5 Oct 2019 \\ Conflicts of Interest: None declared \\ Funding: None \\ *This work has been published under CC BY-NC-SA 1.0 license. \\ Copyright $\subseteq$ Iran University of Medical Sciences
}

Cite this article as: Sajadi HS, Ehsani-Chimeh E, Majdzadeh R. Response to: Letter to the Editor "Universal Health Coverage in Iran: where we stand and how we can move forward". Med J Islam Repub Iran. 2019 (5 Oct);33:106. https://doi.org/10.47176/mjiri.33.106

We thank Joulaei et al (1) for their insightful comments on our paper on Universal Health Coverage in Iran (2). They criticized some parts of Iran's Health Transformation Plan (HTP), and we do not disagree with some of their comments on HTP. However, we think that an evidencebased approach is needed for an in-depth analysis of HTP, which is beyond our correspondence and Joulaei et al.'s comments. Therefore, we only focus on the criticisms made to our correspondence which was related to the starting point of HTP as to whether public hospitals were an appropriate starting point or whether the primary health care (PHC) should have been the starting point for HTP.

While we believe that strengthening PHC is a strategic approach and vital to achieve Universal Health Coverage (UHC), at the same time, starting HTP from hospital services was a tactically correct decision, as public policymakers were looking for a showcase of using targeted subsidies funds to do something sensible for people in social welfare. The inpatient services were an urgent challenge which caused extreme public dissatisfaction. Much earlier, the first measure taken in the health transformation plan of Turkey was prohibition of holding the corpse hostage in hospitals due to unpaid hospital costs. While this was not a significant intervention for strengthening the health system, it softened the ugly face of the system and had tangible results for people. The second reason was the ease of implementing interventions in hospital services; $70 \%$ of outpatient services are provided by the private sector in Iran, which is not well-manageable by the government. In contrast, the public sector is the largest provider of inpatient services, providing inpatient care to almost $80 \%$ of the population. As a result, intervention in public hospitals, compared to outpatient services, has been more feasible. The third reason was the chance of achiev- ing the desired results in a shorter time. The impacts of promotive and preventive measures appear in the longterm, while curative affair measures have short-term impacts.

In sum, we entirely agree that reform is useful when it addresses the most fundamental challenges of the health system. However, the progressive realization of UHC is a crucial principle, meaning that the reform should be a long-term plan which must gradually be evolved (3). Starting HTP from the public hospital should not be considered as a disadvantage since, in reality, it has attracted enough attention and support; however, HTP should have not ended up in the hospital, and it had to address other aspects that were essential for a fundamental transformation such as PHC.

\section{Conflict of Interests}

The authors declare that they have no competing interests.

\section{References}

1. Joulaei H, Fardid M, Bagheri Lankarani K. What we can learn from Health Transformation Plan. Med J Islam Repub Iran. 2019 (28 Sep);33:102.

2. Sajadi HS, Majdzadeh R. From primary health care to universal health coverage in the Islamic Republic of Iran: a journey of four decades. Arch Iran Med. 2019;22(5):262-268.

3. Baltussen R, Jansen MP, Bijlmakers L, Tromp N, Yamin AE, Norheim OF. Progressive realisation of universal health coverage: what are the required processes and evidence? BMJ Glob Health. 2017;2(3):e000342. 